\title{
PENTINGNYA MENJAGA PERAWATAN CENTRAL AIR CONDITIONER SESUAI PETUNJUK MANUAL BOOK DI KAPAL M.V TUNA QUEEN
}

\author{
Yeyen Herlina $^{1 *}$, Teni Hadiyani ${ }^{1}$, Abdurohman ${ }^{1}$ \\ ${ }^{1}$ Program studi Teknika, Akademi Maritim Suaka Bahari Cirebon \\ Jl. Jend. Sudirman No. 156 Ciperna, Kec. Talun, Cirebon \\ "Email: yeyen.herlina@akmicirebon.ac.id
}

\begin{abstract}
Abstrak
Dengan mesin penyejuk udara ini pengaturan udara dalam ruangan akomodasi kapal dapat dilakukan sesuai dengan suhu ruang akomodasi yang diinginkan. Tujuan dari penelitian ini adalah untuk mengetahui mengapa tidak tercapainya suhu ruangan akomodasi yang diharapkan, faktor apa apa yang membuat tekanan kondensor menjadi tinggi dan penyebab penanganan air conditioner di kapal tidak optimal. Sistem air conditioner kurang mendapat perawatan dan pemeliharaan yang teratur, sehingga proses pendinginan terganggu. Sistem Air Conditioner belum bekerja dengan baik karena kurangnya dilakukan pengawasanpengawasan yang rutin dan pengecekan terhadap temperatur, tekanan dan bagian-bagian pendukung lainnya dari sistim. Masinis kurang pengetahuan baik teori maupun praktek, dan belum berpengalaman sehingga gangguan-gangguan yang terjadi sebetulnya tidak seberapa, namun menjadi kerusakan yang lebih besar dan akhirnya mengganggu kinerja sistem air conditioner secara keseluruhan. Belum dilaksanakannya perawatan dan pemeliharaan yang teratur dan terencana sehingga setiap kegiatan tidak tercatat (di dalam log book) sehingga sulit bagi seorang Masinis untuk menganalisa kerusakan yang terjadi dan apa tindakan selanjutnya yang harus dilakukan.
\end{abstract}

Kata kunci: Air conditioner central; Manual book; Perawatan

\section{PENDAHULUAN}

Pada kapal-kapal yang melayani pelayaran di daerah tropis, akan merasakan suhu ruang akomodasi yang kurang nyaman. Telah kita ketahui bersama bahwa kontruksi bangunan sebuah kapal niaga maupun kapal penumpang, saat ini banyak terbuat dari bahan besi maupun bahan baja. Begitupun kontruksi bangunan pada ruang akomodasi dan anjungan (Bridge). Dibutuhkan suatu alat yang dapat membuat keadaan udara sekelilingnya menjadi lebih baik. Salah satu alat tersebut adalah mesin penyejuk udara (Air Conditioner). Dengan mesin penyejuk udara ini pengaturan udara dalam ruangan akomodasi kapal dapat dilakukan sesuai dengan suhu ruang akomodasi yang diinginkan. Dalam mengatur udara diperlukan 6 (enam), macam pengaturan-pengaturan tersebut meliputi :

1. Suhu udara (temperature)

2. Kelembaban (humadity)

3. Aliran Udara (air motion)
4. Membersihkan Udara (air cleaning)

5. Ventilasi dari Udara Luar (fresh air ventilation)

6. Mengeluarkan Udara Kotor (exhaust)

Dengan demikian udara yang sejuk dan nyaman pada ruang akomodasi akan dapat tercapai, yang akhirnya akan berpengaruh baik terhadap produktifitas dan aktifitas awak kapal, sehingga pengoperasian kapal akan dapat berjalan dengan baik.

Kapal MV. Tuna Queen beroperasi di Marocco (Eropa) guna keperluan bongkar muat di wilayah tersebut, tiba-tiba sistem Air Conditioner di atas kapal menunjukkan tanda-tanda bahwa kinerjanya kurang optimal. Sehingga semua kru tidak merasa nyaman berada dalam ruangan akibat suhu kamar meningkat hingga $30^{\circ} \mathrm{C}$ dari seharusnya suhu normal berkisar antara $18^{\circ} \mathrm{C}$ sampai $25^{\circ} \mathrm{C}$. Kemudian diadakan pengamatan terhadap sistem Air Conditioner. Dari hasil pemantauan, ternyata benar bahwa kinerja sistem Air 
Conditioner kurang optimal sebab kompresor terus menerus bekerja tanpa henti, tapi suhu di dalam ruangan tetap tidak tercapai sesuai yang diharapkan. Bila sistem dalam keadaan normal pada saat beroperasi, dan suhu yang ditentukan telah tercapai di dalam ruangan maka sistem akan berhenti secara otomatis dengan cara pemutusan arus listrik oleh termostart kepada motor kompresor . Dan sistem akan beroperasi kembali bila suhu ruangan naik . Demikianlah siklus kerja secara berulang, bila sistem Air Conditioner bekerja secara normal. Seperti pada keadaan yang telah dijelaskan di atas tadi, maka diadakanlah pemeriksaan-pemeriksaan terhadap sistem Air Conditioner. Penutup ruang coil pendingin dibuka dan diperiksa, ternyata di permukaan coil-coil pendingin diselimuti oleh bunga es. Es yang menyelimuti coilcoil pendingin dibersihkan dengan cara menyemprotkan air (water defrost) keseluruhan permukaan es pada pipa-pipa evaporator. Setelah coil-coil pendingin (evaporator) bersih maka sistem Air Conditioner kembali dijalankan (di-on). Dalam hasil kerjanya keadaan dan permasalahannya tetap sama seperti keadaan semula, yaitu sistem tetap bekerja tanpa berhenti dan suhu kamar tetap tidak nyaman karena bunga-bunga es tetap timbul menyelimuti coil-coil pendingin mengakibatkan kelancaran gerakan aliran udara melewati coil-coil pendingin terhalang. Oleh karena itu, udara hasil daripada proses pendinginan yang disalurkan melalui terowongan udara (air $d u c t$ ) ke ruangan, namun suhunya tetap tidak sesuai dengan kebutuhan, yaitu tidak sejuk dan tidak nyaman. Untuk mengetahui secara pasti maka dilakukan pengumpulan refrigerant yang beredar di dalam sistem ke receiver (kondensor), hal ini umum disebut dengan istilah pump down. Pengumpulan bahan pendingin ini dilakukan apabila pada salah satu alat pada instalasi pendingin diduga fungsinya abnormal. Dan hasil pemeriksaan, dipastikan bahwa dryer filter kotor dan diganti dengan dryer filter yang baru. Setelah selesai penggantian maka sistem Air Conditioner kembali dijalankan dan hasilnya memuaskan.

Adanya gangguan pada instalasi Air Conditioner akibat dari salah satu Komponen yang rusak atau tidak optimal bekerja pada instalasi Air Conditioner. Instalasi Air Conditioner terdiri dari peralatan yang berlainan fungsi. Adapun gangguan yang pernah dialami adalah tidak optimalnya kerja dari pada kondensor. Seperti diketahui fungsi utama kondensor adalah memindahkan kalor menurunkan panas dari refrigerant, sehingga media pendingin yang di kompresikan oleh kompressor dapat merubah wujud media pendingin dari gas menjadi cair dengan cara mendinginkan gas freon yang berada di dalam kondensor tersebut. Hal yang sering terjadi adalah adanya kotoran yang terdapat pada pipa-pipa pendinginan sehingga penyerapan panas menjadi berkurang dan tekanan pada kondensor menjadi tinggi.

\section{LANDASAN TEORI}

Hartanto (1985) menyimpulkan bahwa prinsip kerja Air Conditioner pemampatan (kompresi) yaitu uap refrigerant lewat panas bersuhu dan tekanan rendah yang berasal dari proses pengupan dimampatkan oleh kompresor menjadi uap bersuhu dan bertekanan tinggi agar kemudian mudah diembunkan, uap kembali menjadi cairan di dalam kondensor. Proses pengembunan adalah proses pengenyahan atau pemindahan panas dari uap refrigerant bersuhu dan bertekanan tinggi hasil pemampatan kompresor ke media pengembun di luar kondensor.

Arismunandar dan Saito (2005), penempatan evaporator dibedakan menjadi empat macam sesuai dengan keadaan refrigerant di dalamnya, yaitu : 1) Evaporator kering (dry expansion evaporator) 2) Evaporator setengah basah 3) Evaporator basah (flooded evaporator) 4) Sistem pompa cairan. Pada evaporator kering, cairan refrigerant yang masuk ke 
dalam evaporator sudah dalam keadaan campuran cair dan uap, sehingga keluar dari evaporator dalam keadaan uap kering, karena sebagian besar dari evaporator terisi uap maka penyerapan kalor tidak terlalu besar jika dibandingkan dengan evaporator basah. Evaporator kering tidak memerlukan banyak refrigerant, di samping itu jumlah minyak pelumas yang tertinggal di dalam evaporator sangat kecil (Arismunandar dan Saito,2005). Pada evaporator jenis setengah basah, kondisi refrigerant di antara evaporator jenis ekspansi kering dan evaporator jenis basah.Pada evaporator basah terdapat sebuah akumulator untuk menampung refrigerant cair dan gas, dari akumulator tersebut bahan pendingin cair mengalir ke evaporator dan menguap di dalamnya. Sisa refrigerant yang tidak sempat menguap di evaporator kembali ke dalam akumulator, di dalam akumulator refrigerant cair berada di bawah tabung sedangkan yang berupa gas berada di atas tabung.



\section{Gambar 1. Sistem Pendingin Ruang Akomodasi Di Kapal}

Gambar di atas ialah sebuah instalasi pendingin yang sederhana, artinya tidak dilengkapi dengan otomat-otomat. Suatu instalasi pendingin di atas adalah suatu instalasi mekanik yang menggunakan suatu cairan pendingin untuk mengambil panas. Cairan tersebut pada masa mi banyak dipergunakan ialah freon 12 dan freon 22.Dalam kapal niaga biasa, jadi bukan niaga yang khusus mengangkut daging, telur, mentega dan lain-lain, dipergunakan freon 12 sebagai pendingin.

Freon (12) ialah suatu jenis freon dari beberapa deretan freon yang mempunyai titik didih $-29,8^{\circ} \mathrm{C}$ pada tekanan atmosfir sedangkan freon (22) mempunyai titik didih $-40^{\circ} \mathrm{C}$ dan dipakai di kapal-kapal yang mengangkut daging (deep freeze) atau barang-barang lainnya yang harus didinginkan pada suhu yang rendah sekali. Peredaran freon ini dapat dibagi dalam dua bagian yaitu bagian tekanan tinggi dan bagian tekanan rendah

Pada bagian tekanan tinggi jalannya peredaran ialah melalui kompresor, pemisah minyak, kondensor, penampung.dan terns ke klep ekspansi. Pada bagian tekanan rendah jalannya peredaran ialah melalui klep ekspansi, evaporator, dan selanjutnya kembali lagi ke kompresor. Penjelasan-penjelasan bagianbagian yang tersebut di atas gunanya ialah untuk memudahkan penyelidikan kita bila terjadi gangguan yang tidak diinginkan.

Jalannya proses pendinginan sebagai berikut : Kompresor kita jalankan.la menghisap gas freon dari evaporator yang mempunyai tekanan rendah dan dikeluarkan dari kompresor dengan tekanan tinggi. Freon yang keluar dari kompresor bersifat gas dan cairan dengan suhu yang tinggi. la mengalir melalui pemisah minyak.Karena freon itu lebih ringan dari pada minyak, maka minyak itu selalu berada dibawah. Minyak dialirkan kembali ke kompresor dari bagian bawah tabung pemisah melalui pipa kecil yang dihubungkan dengan karter (bag.bawah) kompresor. Adanya minyak ikut didalam peredaran, ialah disebabkan pelumuran pada kompresor seperti bantalan-bantalan, ring-ring torak dengan silinder-silinder.

Freon yang telah dipisahkan dari minyak mengalir kekondensor. Dalam kondensr freon didinginkan dengan air laut dengan perantara pompa pendingin. Freon yang didinginkan itu menjadi cair untuk selanjutnya ditampung didalam sebuah pelampung (receiver). Cairan freon 
selanjutnya mengalir keklep ekspansi dengan melalui dehidrator atau pengering.

Dari klep ekspansi freon dialirkan kedalam ruangan (atau pipa-pipa) yang mempunyai tekanan lebijh rendah agar mengembang. Pengembangan inilah yang diperiukan untuk menghisap panas yang berada diruang beku. Ruangan atau pipapipa beku itu disebut evaporator atau penguap freon. Selanjutnya gas freon dihisap kembali kekompresor. Pada instalasi jaman sekarang apalagi yang terdapat pada kapal-kapal niaga, maka untuk menghemat tenaga serta mencegah kerusakan, instalasi tersebut dilengkapi dengan otomat-otomat yang maksudnya untuk memudahkan pengawasan dan baik atau tidaknya jalannya instalasi.

Sebagai telah diterangkan sebelumnya gas meninggalkan kompresor dengan tekanan tinggi dan suhu tinggi. Adalah menjadi tugasnya kondensor untuk merubah gas freon yang panas menjadi freon yang cair untuk selanjutnya digunakan kembali dalam proses pendinginan.

Ilyas (1993) menyimpulkan bahwa pengembun atau kondensor adalah bagian dari refrigerasi yang menerima uap refrigerant tekanan tinggi yang panas dari kompresor dan mengenyahkan panas pengembunan itu dengan cara mendinginkan uap refrigerant tekanan tinggi yang panas ke titik embunnya dengan cara mengenyahkan panas sensibelnya. Pengenyahan selanjutnya panas laten menyebabkan uap itu mengembun menjadi cairan.

Kondensor itu ada 2 macam yaitu Kondensor dengan pendingin udara yang biasanya digunakan pada instalasi kecil seperti lemari es, lemari air dingin dan lainlain serta kondensor dengan pendingin air biasa atau air laut yang sering dipakai dikapal-kapal niaga. Kondensor jenis Nomer 2 akan kami terangkan dibawah ini yaitu Kondensor freon dengan pendinginan air umumnya terdiri dari sebuah silinder dengan berpuluh-puluh pipa yang didalamnya dialirkan air pendingin.Gas-gas yang panas dialirkan didalam silmder itu dan selanjutnya mengembun (menjadi cair) bila gas-gas tersebut mengenai dinding luar dari pipa pendingin.

Konstruksi kondensor juga ada dua macam yaitu kondensor yang menggunakan pipa-pipa berbentuk $U$ dan dirol pada pelatpelat pipa-pipa untuk mencegah kebocoran serta kondensor yang menggunakan piappipa lums dan pada tiap-tiap ujungnya disolder perak pada pelat pipa-pipa .

\section{METODE}

Metode penelitian dilakukan dengan cara deskriptif kualitatif. Pendekatan deskriptif kualitatif adalah suatau proses penelitian dan pemahaman yang berdasarkan metodologi yang menyelidiki suatu fenomena masalah yang terjadi, penelitian membuat suatu gambaran komplek, meneliti , laporan terperinci dari pandangan responden, dan melakukan studi pada situasi yang dialami. Prosedur penelitian yang menghasilkan data deskriptif berupa kata-kata tertulis maupun lisan dari orang dan pelaku yang diamati. Penelitian kualitatif digunakan jika masalah belum jelas, untuk mengetahui makna yang tersembunyi, untuk memahami masalah, untuk mengembangkan teori dan memastikan kebenaran.

\section{HASIL DAN PEMBAHASAN \\ Kinerja Air Conditioner Kembali Optimal}

Untuk mengoptimalkan kembali kinerja Air Conditioner (Air Condition System) di antaranya membersihkan (water defrost) penumpukan es yang menyelimuti coil-coil pendingin pada pipa-pipa evaporator. Dan jika usaha ini belum memecahkan masalah dilakukan pump down untuk pemeriksaan instalasi pendingin yang fungsinya abnormal. Dari hasil pemeriksaan, dipastikan bahwa dryer filter kotor dan diganti dengan dryer filter yang baru. Setelah selesai penggantian maka kinerja sistem Air Conditioner kembali optimal dan hasilnya memuaskan, 
karena udara yang dihasilkan daripada proses pendinginan dari sistem Air Conditioner yang disalurkan melalui pipapipa ke ruang-ruang suhunya sudah sesuai dengan kebutuhan, yaitu menyejukkan dan menyamankan suasana kerja di atas kapal.

\section{Gangguan Pada Instatasi Dapat Diatasi}

Untuk mendapatkan efisiensi yang baik pada sistem Air Conditioner sehingga gangguan pada instalasi dapat diatasi dan tidak terdapat gangguan serupa pada instalasi sistem Air Conditioner tersebut diwaktu mendatang, maka perlunya perawatan berkala yang teratur dan berencana pada bagian-bagian sistem Air Conditioner terutama pada kompressor dan sistem pendukungnya seperti kondensor. Tekananan buang kompressor yang terlalu tinggi ,penyebabnya adalah tekanan air pendingin yang kurang dan kondensor yang kotor. Dalam pemeriksaan pada kedua bagian tersebut, kondensor dan saringan isap pompa air pendingin dalam keadaan kotor. Upaya yang dilakukan pada kondensor dalam pembersihan lubanglubang pipa air pendingin dan bila perlu dilakukan penggantian zinc anoda. Kerusakan kondensor biasanya adalah penyumbatan lubang-lubang pipa air pendingin oleh lumpur atau kotoran lain sehingga dapat mengganggu penyerapan panas. Gangguan pada instalasi ini dapat diatasi dengan pembersih- an pada kondensor yang dilakukan dengan memakai sikat khusus atau rotan. Apabila sudah bersih maka sebelum ditutup kembali, sangat perlu cover dicat anti karat dan zinc anoda diganti. Setelah langkah ini selesai, maka sistem Air Conditioner dapat dijalankan dan sistem bekerja normal pada proses kerjanya sebagaimana yang diharapkan.

Pump Down dan Penceratan Udara Melalui Katup Cerat dari Pada Kondensor. Untuk mengetahui adanya udara dalam sistem Air Conditioner dapat dilakukan dengan pump down, yang dimaksud dengan pump down ialah mengumpulkan semua freon ke dalam kondensor. Maksudnya agar freon terkondensasi di dalam kondensor sehingga mudah untuk membuang udara dari padanya. Biarkan media pendingin mengalir terus sehingga bahaya pendingin di dalam kondensor menjadi dingin. Kemudian bandingkan suhu bahan pendingin dengan suhu air laut keluar kondenser. Jika suhu bahan pendingin lebih tinggi $5^{\circ} \mathrm{C}$ atau lebih dibandingkan dengan suhu air laut, maka hal ini menunjukkan bahwa udara terdapat dalam sistem. Untuk membuang udara tersebut, buka kran cerat (air purge cock) yang terdapat di atas kondensor secara sedikit demi sedikit sampai sedikit bahan pendingin ikut terbuang. Adapun tata cara pembuangan udara dan dalam sistem sebagai berikut : a. Tutup kran setelah kondensor. b. Jalankan kompressor dan tunggu sampai vakum. c. Bila sudah vakum berarti refrigerant semuanya berkumpul di dalam kondensor. d. Matikan kompressor dan jalankan terus pedinginan air laut untuk kondensor. e. Tunggu beberapa menit/setengah jam agar gas freon berubah menjadi cair. f. Bila gas Freon telah berubah menjadi cair berarti cairan freon berada di bawah dan udara berada di atas. g. Kemudian buka kran pembuangan udara yang berada di atas kondensor, maka udara akan keluar dengan sendirinya. h. Bila pembuangan udara telah dilakukan maka buka kran yang semula dapat bersirkulasi kembali dalam sistem. Baik buruknya kerja dari suatu sistem Air Conditioner di atas kapal ditentukan oleh hasil kerja dari peralatan-peralatan sistem itu sendiri dan dari penanganan seorang masinis yang benar-benar sudah memakai secara teori dan praktek juga berpengalaman. Di mana peranan dalam penanganan perawatan sangat dominan dan didukung juga dengan kecakapan seorang masinis dalam pengetahuan dan pengalamannya, sehingga dalam pengisian 
freon ke dalam sistem Air Conditioner tidak melebihi dari batas yang ditentukan.Adapun tanda-tanda dari kelebihan bahan pendingin (freon) di dalam sistem adalah : Tekanan yang tampak pada penunjukan meter ganda (charging manifolt). Pada sisi tekanan rendah, tinggi (70 psig) dan pada sisi tekanan tinggi, tinggi (275 psig). Kompressor bersuara berisik, getarannya kuat, amperenya tinggi dan overload. Saringan atau pengering menjadi lebih panas. Saluran hisap dingin dan berkeringat, kadang-kadang dapat ditemukan bunga es. Sistem yang diisi terlalu banyak, selain dapat diketahui dari tanda-tanda tersebut di atas juga dapat diketahui dengan timbulnya bunga es secara merata pada evaporator dan ini dapat hilang kembali, tapi pada saluran hisap sampai dekat kompressor menjadi penuh dengan bunga es. Bila telah demikian keadaannya maka kinerja sistem Air Conditioner terganggu sehingga suhu dalam ruangan tidak dapat lagi dipertahankan. Dalam kondisi seperti ini, apabila sistem tetap dipertahankan untuk bekerja terus maka bahan pendingin cair akan masuk ke dalam kompressor dan ini dapat berakibat fatal, yaitu terjadi kerusakan pada katup-katup kompressor

\section{Pengetahuan Masinis Dalam Penanganan Sistem Air Conditioner}

a. Meningkatkan Pengetahuan Masinis Mengenai Sistem Air Conditioner

Perawatan serta perbaikan yang dilakukan dan diatur secara manajemen di atas kapal dapat mempermudah menyelesaikan pekerjaan tepat pada waktunya. Untuk menunjang kelangsungan hidup dari sebuah perusahaan pelayaran tertentu sangat erat hubungannya dengan kelancaran pengoperasian., di antara sistem Air Conditioner yang sangat berperan penting dalam kenyamanan para awak Kapal dalam menjalani pekerjaannya, kinerja sistem Air Conditioner yang optimal tidak hanya ditunjang dari perawatan rutin dan terencana dari sistem Air Conditioner tersebut.

Agar kegiatan-kegiatan perawatan sistem Air Conditioner dapat terlaksana tepat pada sasarannya dituntut suatu ketrampilan dari personil (masinis), terutama ketrampilan Managerial (Managerial Skill) dari Kepala Kamar Mesin. Dalam hal ini seorang pimpinan harus mempunyai ketrampilan dalam mengelola dan dituntut kesanggupan profesional untuk memelihara dan menjalankan peralatan-peralatan pendukung di atas kapal secara efisien dan ekonomis. Perlunya masinis meningkatkan pengetahuannya mengenai penanganan sistem Air Conditioner, karena masinis dituntut untuk menjadi sumber daya yang pertimbangan di atas : efektif, efisien dalam membuat rencana-rencana perawatan yang berdasarkan a) Penekanan atas biaya perawatan b) Penekanan biaya operasi kapal c) Peningkatan efisiensi yang tinggi d) Down time yang rendah. Selain itu para masinis dituntut untuk melakukan pendataan dalam menangani perawatan sistem Air Conditioner, seperti membuat laporan pelaksanaan kegiatan-kegiatan yang dilakukan, analisa biaya, pengawasan dan feed back (umpan balik), dan mengetahui sejarah perawatan dari sistem Air Conditioner tersebut. Peningkatan pengetahuan masinis dari segi managerial juga dituntut untuk mengetahui apa yang harus dilakukan dalam perawatan, bagaimana melakukan- nya, kapan pekerjaan tersebut harus dilakukan dan alasan pelaksanaannya.

\section{b. Mempelajari Buku Petunjuk dari Pabrikan}

Dengan banyaknya buku-buku petunjuk di atas kapal yang pada umumnya menggunakan bahasa Inggris maka perlu bagi para masinis untuk dapat, paling sedikit mengerti dan memahami bahasa 
Inggris dalam rangka mengetahui cara pengoperasian dan perawatan dari pada pesawat-pesawat di atas kapal, dalam hal ini adalah sistem Air Conditioner. Menurut buku instruksi bahwa perawatan dan pada sistem Air Conditioner dari pabrik pembuatnya. Di dalam hal ini pabrik pembuat memberikan buku instruksinya kepada pemakai untuk memudahkannya dalam pekerjaan perawatan dan ketentuan jam kerja yang diberikan oleh pabrik pembuat itu dapat dipercaya, karena pabrik pembuat sebelumnya telah melakukan serangkaian percobaan terhadap barang yang telah dibuatnya. Selain dari buku instruksi di dalam melaksanakan pekerjaan perawatan juga harus disesuaikan dengan: a) Rencana kerja yang telah disusun oleh manajemen kapal/ perusahaan. b) Peraturan-peraturan dari minimal setiap 3 bulan sekali harus dilakukan pembongkaran dan pembersihan pada sistem Air Conditioner, tetapi hal ini kadang terabaikan oleh para Masinis yang kurang mengetahui dan tidak mempenhatikan buku petunjuk yang dikeluarkan biroklasifikasi serta undangundang yang mengatur keselamatan jiwa di laut.

\section{c. Dibuat Petunjuk Kerja Cara Perawatan Sistem Air Conditioner}

Perawatan dan perbaikan suatu sistem Air Conditioner di atas kapal dapat diartikan sebagai suatu usaha atau kegiatan yang dilakukan terhadap sistem Air Conditioner di atas kapal, yang dititik beratkan pada ketentuan kerusakan fisik yang ada, dan secara teknis memerlukan perawatan dan perbaikan guna mengembalikan pada kondisi fisik semula atau pada kondisi normal. Sistem perawatan yang baik adalah sistem perawatan yang dilaksanakan dari awal, terencana dan sistematis. Lancarnya pengoperasian kapal secara tidak langsung tergantung dari baik buruknya kondisi sistem Air Conditioner di atas kapal, oleh karena itu kondisi Air
Conditioner tersebut harus selalu dalam keadaan layak untuk dipergunakan, dalam pengoperasiannya diperlukan perawatan yang terencana tetapi yang sering kitahadapi perawatan terhadap sistem Air Conditioner di atas kapal terlambat dan terlupakan. Untuk itu diperlukan adanya petunjuk kerja cara perawatan dan perbaikan secara teratur dan berkesinambungan dari sistem Air Conditioner, karena perawatan dan perbaikan tidak dapat berjalan dengan lancar tanpa adanya suku cadang yang mencukupi, untuk itu perlunya dibuat petunjuk kerja cara perawatan sistem Air Conditioner agar gangguan-gangguan yang timbul dalam pengoperasian sistem Air Conditioner dapat dikurangi atau bahkan dihindari sama sekali, dan permasalahanpermasalahan yang timbul dari sistem Air Conditioner tersebut dimasa mendatang dapat segera diketahui langkah-langkah apa yang harus diambil dalam mengatasi permasalahan tersebut. Diadakan sistem perawatan teratur dan terencana. Perawatan yang dilaksanakan secara teratur pada sistem Air Conditioner akan memungkinkan sistem tersebut berada dalam kondisi yang baik, sehingga akan memberi kesejukan dan kenyamanan para awak di atas kapal dalam menjalankan kegiatannya dan kesiapan para awak kapal yang melayani peralatan kapal juga tetap terjaga. Karena walau bagaimanapun kelancaran pengoperasian suatu kapal sangat tergantung dari rasa aman dan tenang para krunya Agar maksud tersebut di atas tercapai, selain dari kesiapan para awak kapalnya, juga diperlukan suatu perencanaan perawatan yang dibuat dengan pertimbangan-pertimbangan yang matang, serta faktor-faktor lainnya yang perlu diperhatikan. Karena hal itu akan merupakan landasan atau patokan terhadap rencana kerja selanjutnya. Setiap kegiatan perawatan di atas kapal pada umumnya dan perawatan sistem Air Conditioner pada 
khususnya, haruslah direncanakan tertebih dahulu agar kegiatan-kegiatan perawatan tersebut dapat terlaksana secara terarah dan terpadu, karena kegiatan-kegiatan perawatan yang dilakukan tidak terlepas dari pertimbangan-pertimbangan ekonomi atau pertimbangan untung ruginya guna menghindari pemborosan-pemborosan. Sehingga dengan demikian dapat diharapkan upaya penekanan biaya-biaya yang terlalu besar yang dikeluarkan oleh perusahaan yang akhirnya dapat mengganggu kegiatan lainnya dalam pengoperasian kapal dapat dihindari.

\section{KESIMPULAN}

Sistem Air Conditioner kurang mendapat perawatan dan pemeliharaan yang teratur, sehingga proses pendinginan terganggu. Sistem Air Conditioner belum bekerja dengan baik karena kurangnya dilakukan pengawasan-pengawasan yang rutin dan pengecekan terhadap temperatur, tekanan dan bagian-bagian pendukung lainnya dari sistim. Masinis kurang pengetahuan baik teori maupun praktek, dan belum berpengalaman sehingga gangguan-gangguan yang terjadi sebetulnya tidak seberapa, namun menjadi kerusakan yang lebih besar dan akhirnya mengganggu kinerja sistem Air Conditioner secara keseluruhan. Belum dilaksanakannya perawatan dan pemeliharaan yang teratur dan terencana sehingga setiap kegiatan tidak tercatat (di dalam log book) sehingga sulit bagi seorang Masinis untuk menganalisa kerusakan yang terjadi dan apa tindakan selanjutnya yang harus dilakukan seperti para masinis agar memperhatikan masalah perawatan sistem Air Conditioner secara kontinyu, mengetahui catatan sejarah perawatan, perbaikan dan pemeliharaan. Serta mempersiapkannya sesegera mungkin sejak dipakainya peralatan tersebut, para masinis / operator sistem Air Conditioner agar melakukan pengawasan-pengawasan secara rutin dan mengadakan pengecekan terhadap temperatur, tekanan dan bagian bagian pendukung dari sistem Air Conditioner secara periodik agar sistem Air Conditioner dapat bekerja optimal, para operator sistem Air Conditioner agar memahami pengetahuan tentang cara kerja sistem Air Conditioner sebelum melakukan pengoperasian terhadap mesin tersebut, sehingga dapat melakukan penanganan sistem Air Conditioner dengan baik serta Penerapan sistem perawatan rutin dan terencana terhadap Air Conditioner sebaiknya dilakukan sesuai dengan buku petunjuk dari pabrik pembuat mesin tersebut.

\section{DAFTAR PUSTAKA}

Althouse, Andrew D, 1982, Modern Refrigerator And Air Conditioner, Goodheart-wilcot inc., London

Arismunandar, Wiranto, Dan Heizo Saito, 1995, Air Conditioner. Pradnya Paramita, Jakarta

Hamdani, 1994, Metodologi Penelitian, Pustaka Setia, Jakarta.

Handoko, K, 1996, Teknik Room Air Conditioner, PT Ictiar Baru, Jakarta

Lang, Paul V, 1961, Principles Of Air Conditioner, Delmar Cengage Learning, New York.

Ship Book Operating, 1998, Instruction And Manual Book For Air Conditioner, Daikin, Japan. 